\title{
Resist Removal after Photolithography Process Using Adhesive Tape
}

\author{
Tatsuya Kubozono $^{* 1}$, Yutaka Moroishi ${ }^{* 2}$, Yoshio Ohta ${ }^{* 3}$, Noboru Moriuchi ${ }^{* 4}$ \\ *1:Production Engineering Development Center, Nitto Denko Corp., \\ 455-6, Hongo, Minogo, Onomichi,Hiroshima, 722-0212 Japan \\ *2: Core Technology Center, Nitto Denko Corp., 1-1-2,Shimohodumi, Ibaraki, Osaka, 567-8680 Japan \\ *3: Core Technology Center, Nitto Denko Corp., 18, Hirayama, Nakahara, Toyohashi,441-3194Japan \\ *4: Production and Technology Unit, Renesas Technology Corp., Nippon Bldg. \\ 2-6-2, Ote-machi, Chiyoda-ku, Tokyo 100-0004, Japan
}

\begin{abstract}
Resist removal after photolithography in the wafer process was investigated by peeling off the resist layer with an adhesive tape. Compared to conventional $\mathrm{O} 2$ plasma ashing, this new process leaves little contamination, especially metal contamination, on wafers. Consequently, the electrical properties of the oxide layer and substrate were significantly improved. As a result, this new process should be much more effective for the production of front-edge devices while also reducing the usage of harmful liquids. In this paper, the mechanism of the removal is discussed. Ultimately it was determined that the monomer in the adhesive layer penetrated into the resist layer and the two layers were consolidated together. Analytical techniques to detect this phenomenon in situ are also presented.
\end{abstract}

KEYWORDS: removal, resist, photolithography, adhesive tape, plasma ashing, UV/O3 ashing, contamination, damages free, diffusion, in situ observation

\section{Introduction}

Photolithography typically use photoresists to form patterns on a substrate. The conventional processes to remove the resist after patterning are the wet process and the dry process, both of which have some drawbacks which are shown in Table 1.
In the dry process, many recent advances have been realized ${ }^{11)-21)}$ for reducing the damage to the wafer caused by the charged particles in the plasma. However, metallic impurities from the resist often remain on the wafer even after the stripping of organic compounds. In the wet process abundant organic solvents that contain phenolic components

Table1. Problems in the current processes for resist removal after photolithography process ${ }^{1 \text { ) }}{ }^{10}$ )

\begin{tabular}{|c|c|}
\hline & Problems in the current process \\
\hline Dry process & $\begin{array}{l}\text { 1. Implantation of metal impurities contained in resist to the wafer by plasma } \\
\text { bombardment and sputtering can be induced resulting contamination }\end{array}$ \\
\hline \multirow[t]{4}{*}{$\left(\mathrm{O}_{2}\right.$ plasma ashing $)$} & 2. Crystalline defects by charged particles in plasma and UV light by plasma \\
\hline & 3. Charge up of the oxide layer by plasma \\
\hline & 4. Popping and contamination by resist particles \\
\hline & 5. Migration of metallic ions (esp. $\mathrm{Na}$ ) by heating \\
\hline \multirow[t]{2}{*}{ Wet process } & 1. Treatment of waste containing phenolic compounds, strong acids \\
\hline & $\begin{array}{l}\text { 2. Contamination from the chemicals used in the process resulting the } \\
\text { degradation of functions of device by diffusion after the etching processes }\end{array}$ \\
\hline
\end{tabular}


and strong acids must be used which can be problematic. Alternative stripping methods such as using ozone and/or ultra violet (UV) light or lasers exist, however, their stripping rate remains too low to be applied to industrial manufacturing.

In this paper we report a new dry process of removing resist after photolithography by using adhesive tape. The hypothesis of the concept was that the UV curable monomer contained in the adhesive tape can diffuse through resist layer, which then can be consolidated with resist by UV irradiation and delaminated together ${ }^{22)}$. The results of evaluation and the method to estimate diffusivity of monomer through the resist layer in an effort to design a proper adhesive system are reported. The process can be applied to resist removal used in photolithography processes in which ion is implanted less than $1 \mathrm{e} 13$ ions $\square \mathrm{cm}^{-2}$. The removal of the resist implanted by high dose and high energy ions is another demand, and the removal process was reported elsewhere ${ }^{23)}$, whose mechanism was different from that reported in this paper.

\section{Experimental}

The examined process is shown in Figure1.

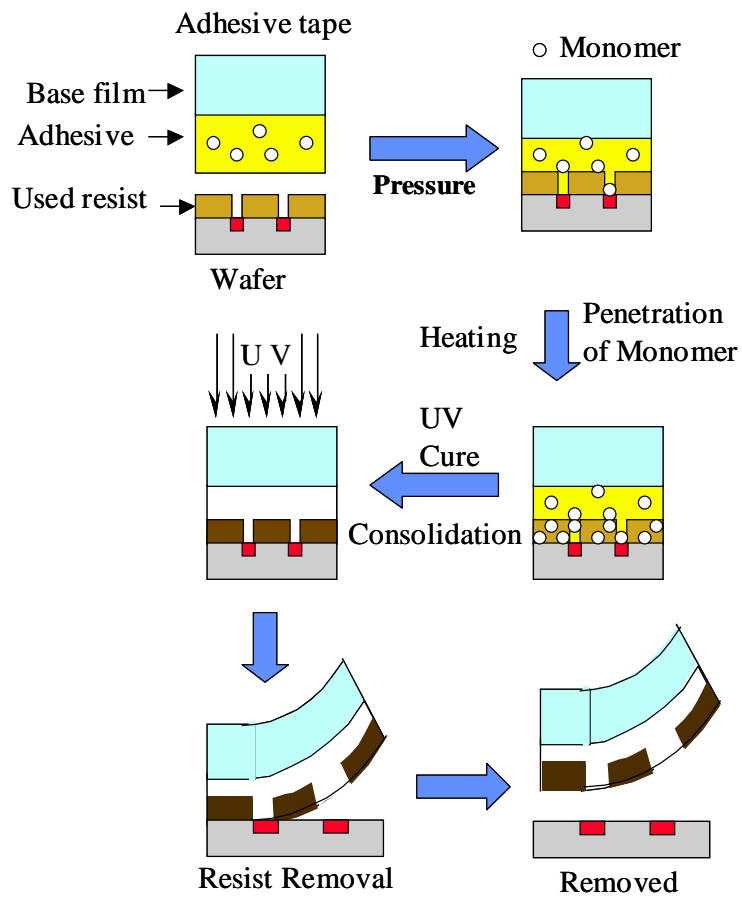

Fig.1 Resist removal by the adhesive tape

2.1 Preparation of resist removal tape (RRT)

The adhesive was cast at a thickness of $40 \mu \mathrm{m}$ from toluene solution on a $50 \mu \mathrm{m}$ thick polyester film. The components of adhesive are shown in
Table 2.

Table 2. Material used in RRT

\begin{tabular}{|l|l|}
\hline \multicolumn{1}{|c|}{ Parts } & \multicolumn{1}{c|}{ Material } \\
\hline Polymer & Buthylacrylate / Acryilonitrile co-polymer \\
\hline Monomer & $\begin{array}{l}\text { Polyethyleneglycoldiacrylate } \\
\text { (Shin-Nakamura Chemicals NK-A600) } \\
\text { Polyethyleneglycoldimethacrylate } \\
\text { (Shin-Nakamura Chemicals NK-4G) }\end{array}$ \\
\hline Initiator & $\begin{array}{l}\text { Benzyl ketal } \\
\text { (Ciba Fine Chemicals Irgacure 184) }\end{array}$ \\
\hline $\begin{array}{l}\text { Crosslinking } \\
\text { agent }\end{array}$ & $\begin{array}{l}\text { Trimethylolpropane tris (tolylenedi } \\
\text {-isocyanate) (Nippon Polyurethane Co.) }\end{array}$ \\
\hline
\end{tabular}

\subsection{Preparation of test wafer with photoresist}

Posi-tone phenolnovolak / naphthaquinonediazide photoresist (JSR PF1X570EDM9) was spin-coated on 5" diameter Si wafer P (100) $1-100 \Omega \mathrm{cm}$ at $0.9 \mu \mathrm{m}$ thickness to evaluate performance of the resist removal process. The wafers with patterned resist (WPR) were prepared using the procedure shown in Table 3. A 5" diameter Si wafer $\mathrm{P}(100) 1-100 \Omega \mathrm{cm}$ without photoresist was used as a control. In this paper

Table 3. Preparation of test wafer

\begin{tabular}{|l|l|}
\hline \multicolumn{1}{|c|}{ Process } & \multicolumn{1}{c|}{ Condition } \\
\hline Substrate & " Si wafer P $(100) 1-100 \Omega \mathrm{cm}$ \\
\hline HMDS treatment & $353 \mathrm{~K} \times 1 \mathrm{~min}+463 \mathrm{~K} \times 2 \mathrm{~min}^{\mathrm{R}}$ \\
\hline Coating of resist & $\begin{array}{l}\text { PFRIX570EDM9 } \\
\text { at } 0.9 \mu \mathrm{m}\end{array}$ \\
\hline Prebake & $373 \mathrm{~K} \times 2 \mathrm{~min}$ \\
\hline Exposure & Test pattern by i-line \\
\hline Post exposure bake & $383 \mathrm{~K} \times 4 \mathrm{~min}$ \\
\hline Peripheral exposure & about $3.6 \mathrm{~mm}$ wide by i-line \\
\hline Development & TMAH $2.38 \% \times 1 \mathrm{~min}$ \\
\hline Rinse & DI water $\times 1 \mathrm{~min}^{\mathrm{R}}$ \\
\hline Post bake & $383 \mathrm{~K} \times 4 \mathrm{~min}^{-2}, 80 \mathrm{keV}$ \\
\hline Ion implantation & P $1 \mathrm{E} 12$ ions.cm \\
\hline
\end{tabular}

* HMDS: Hexamethyldisilazane

TMAH: Tetramethylammoniumhydroxide

patterned resists prepared according to the conditions described in Table3 unless otherwise noted. 
2.3 Resist coated prism for attenuated total reflection spectroscopy (ATR)

The photoresist was spin-coated on a trapezoidal Ge prism $(52 \times 20 \times 2 \mathrm{~mm})$ at $1 \mu \mathrm{m}$ thick to study mechanism of exfoliation of the photoresist by ATR. The coated photoresist was dried in air at $383 \mathrm{~K}$, $403 \mathrm{~K}, 423 \mathrm{~K}$, and $453 \mathrm{~K}$ typically for 10 minutes.

\subsection{Resist removal from wafer}

Resist remover system RR-500R was used for the lamination of RRT to wafers and delamination of RRT with the resist from wafers. RR-500R was a prototype machine designed for this process by Nitto Denko Co.

The procedure of resist removal was:

1. Load and align the wafer by robotic hand

2. Lamination of RRT to the wafer on the table at $403 \mathrm{~K}$ by a roll laminator

3 . Heating typically at $403 \mathrm{~K}$ for a few minutes

4. Irradiation by UV light of a high-pressure mercury lamp by $1 \mathrm{~J} \cdot \mathrm{cm}^{-2}$

5. Delamination of RRT with the resist from wafer

6 . Unload the wafer by robotic hand

In this paper, all experiments were carried out with the "resist removal process" procedure shown above, unless otherwise noted. Details of the experiments, equipment and measurements are described in the results.

\section{Results}

3.1 Change of the profile of the resist pattern by resist removal process

Though no residue on the wafer after the resist removal process was found by observation of optical microscopy, the profile of the resist pattern was measured by the surface profiler. (Tencol Co., Surface Profiler P-10). The resist had sharp edges to $900 \mathrm{~nm}$ deep before the removal, but there was no pattern edge at the same position after the resist removal.

Three kinds of wafers were examined after the resist removal process: the controlled wafer without resist, the wafer with implanted resist but not patterned, and patterned resist. Particulate residue over $0.2 \mu \mathrm{m}$ in diameter was measured by Particle checker LS-5000 (Hitachi DECO).

After delamination from the control wafer, the particulate residue over $0.2 \mu \mathrm{m}$ diameter on the 5 " wafer surface measured less than 10 counts. For the wafers with resist, patterned and not patterned, complete filling of the adhesive along the resist patterns was necessary and slow lamination of the tape and plenty irradiation of UV light were needed to reduce the residues to similar counts as seen in the control wafer.

\subsection{Metallic contamination after resist removal process}

The metallic contamination on the wafer surface after the resist removal process was measured by total reflection X-ray fluorescence (TXRF).

The control wafer and WPR were subjected to the resist removal process using RRT. Photoresist on WPR was removed by $\mathrm{O}_{2}$ plasma ashing as a reference to evaluate metallic contamination after the resist removal process by RRT. The detailed conditions of measurements and the results were described in Table 4. The comparison of two different resist removal processes were listed as Table 5. After the resist removal process by RRT, metallic contamination on the wafer surface was in the order of $10^{9}$ atom $\cdot \mathrm{cm}^{-2}$. While, applying the resist removal process to the controlled wafer, the elements $S$ and $K$ were transferred, but the contamination of other transition metals were transferred less than $10^{10}$ atoms $\cdot \mathrm{cm}^{-2}$. Otherwise, there was remarkable difference in transferred $\mathrm{Cr}$, $\mathrm{Mn}, \mathrm{Fe}$ and $\mathrm{Ni}$ on the wafer treated by $\mathrm{O}_{2}$ plasma ashing. Especially $\mathrm{Mn}$ and $\mathrm{Fe}$ were detected at the order of $10^{11}$ atoms $\mathrm{cm}^{-2}$. It is assumed that the impurities of the resist remained on the wafer after ashing and/or they were generated from the circumstances of $\mathrm{O}_{2}$ plasma asher.

Table 4. Metallic contamination on wafers after resist removal process

\begin{tabular}{|c|c|c|c|c|c|c|c|c|c|c|}
\hline & $\mathrm{S}-\mathrm{K} \alpha$ & $\mathrm{Cl}-\mathrm{K} \alpha$ & $\mathrm{K}-\mathrm{K} \alpha$ & $\mathrm{Ca}-\mathrm{K} \alpha$ & $\mathrm{Cr}-\mathrm{K} \alpha$ & $\mathrm{Mn}-\mathrm{K} \alpha$ & $\mathrm{Fe}-\mathrm{K} \alpha$ & $\mathrm{Ni}-\mathrm{K} \alpha$ & $\mathrm{Cu}-\mathrm{K} \alpha$ & $\mathrm{Zn}-\mathrm{K} \alpha$ \\
\hline & \multicolumn{10}{|c|}{$\mathrm{e} 10$ atom $\cdot \mathrm{cm}^{-2}$} \\
\hline $\mathrm{RRT}^{* 1}$ & 56.4 & 5.6 & - & - & - & 0.11 & 0.57 & 0.61 & - & 0.52 \\
\hline $\mathrm{O}_{2}$ Plasma Ashing ${ }^{*}$ & 1680 & 1010 & - & - & 4.62 & 11.6 & 12.3 & 7.52 & - & 22.7 \\
\hline Controlled Wafer ${ }^{* 2}$ & 317 & 15.7 & 3.81 & 0.45 & 0.27 & 0.20 & 1.23 & 0.44 & 0.23 & 0.55 \\
\hline
\end{tabular}

- : Under the quantified limit

*1: Equipment : TREX 610T (Technos Co.)

$\mathrm{W}-\mathrm{L} \beta \varphi=0.05^{\circ} \quad$ Measuring time $=500 \mathrm{~s}$

*2: Equipment : System 3700 (Rigaku Co.)

$\mathrm{Au}-\mathrm{L} \beta \quad \varphi=0.08^{\circ} \quad$ Measuring time $=500 \mathrm{~s}$ 


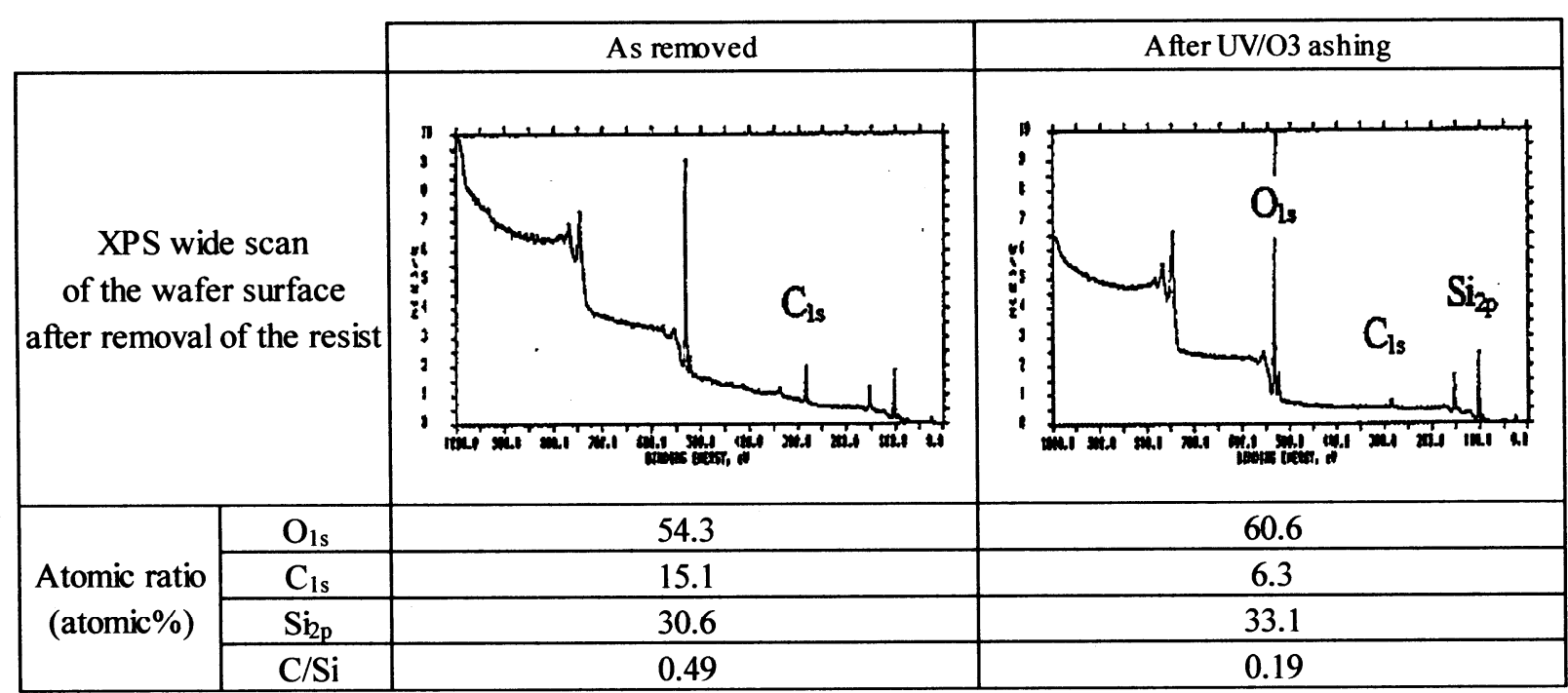

Figure 2. Atomic composition of the surface of wafers before and after $\mathrm{UV} / \mathrm{O}_{3}$ ashing
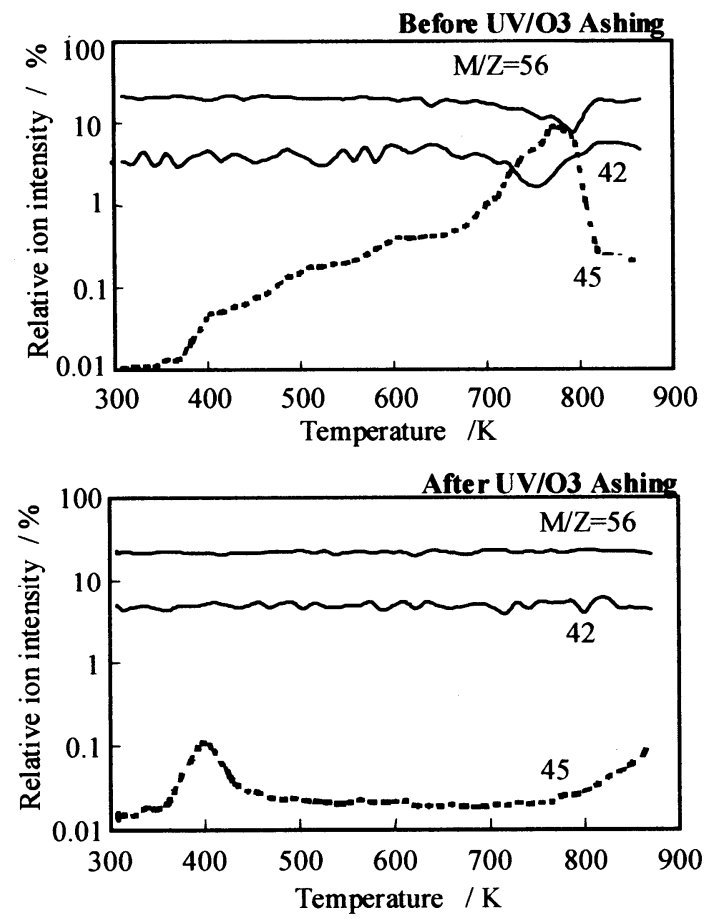

Figure 3. TDS-APIMS spectra of the wafer surface before and after $\mathrm{UV} / \mathrm{O}_{6}$ ashing

\subsection{Observation of the wafer surface after removal by RRT}

An organic thin layer less than $5 \mathrm{~nm}$ thick was found on the wafer after the resist removal process by RRT. The analyses were carried out by X-ray photoelectron Spectroscopy (XPS), ULVAC-PHI ESCA5400, for the surface and transmission electron microscope (TEM), H-800 (Hitachi Ltd.) at the acceleration voltage of $100 \mathrm{kV}$, for the cross section of the wafer. The X-ray source of XPS was
$\mathrm{Mg} \mathrm{K} \alpha$ (non-monochrometer) and its power was $15 \mathrm{KV}, 20 \mathrm{~mA}(300 \mathrm{~W})$.

The organic thin layer observed on the wafer was a mixture of the resist and the monomer contained in the adhesive, so it was hypothesized that the monomer penetrated into the resist layer, and dissolved it. The destruction of the resist layer took place at the inside of the resist and adhesive mixture, and remained the organic thin layer on the wafer.

Light $\mathrm{UV} / \mathrm{O}_{3}$ ashing was effective to take off the organic thin layer from the observation by field emission scanning electron microscope (FE-SEM: Hitachi Ltd. S-4000, Acceleration Voltage 1.5kV). Confirmation was held by XPS and thermal desorption spectroscopy - atmospheric pressure ionized mass spectroscopy (TDS-APIMS: Hitachi Ltd.), measuring the wafer surface before and after $\mathrm{UV} / \mathrm{O}_{3}$ ashing. The result of the measurement of XPS is shown in Figure 2, where the observed carbon on the wafer was reduced by $\mathrm{UV} / \mathrm{O}_{3}$ ashing. The remaining carbon observed on the wafer surface after $\mathrm{UV} / \mathrm{O}_{3}$ ashing was caused by the handling in the measurement, and was the same level as the control wafer.

TDS-APIMS measurements were carried out on the wafers prepared as the same way described in the former section. The results of the TDS-APIMS measurements were shown in Figure 3.

The equipment of TDS-APIMS was a prototype that was constructed in Hitachi Ltd. which combined UG-20 for TDS and UG-240 for APIMS (both are manufactured by Hitachi Tokyo Electronics Co., Ltd.). The analysis was carried out under $\mathrm{N}_{2}$ carrier gas at $41 \cdot \mathrm{min}^{-1}$, and a heating speed of $10 \mathrm{~K} \cdot \mathrm{min}^{-1}$ for positive ions of a m/z between 3 and 150 . The spectra gained after $\mathrm{UV} / \mathrm{O}_{3}$ 
Table 5. Comparison of electric properties between resist removal processes

\begin{tabular}{|c|c|c|c|}
\hline PREPARATION & $\begin{array}{l}\text { RRT } \\
\text { (A) }\end{array}$ & $\begin{array}{l}\mathrm{O}_{2} \text { plasma } \\
\text { ashing } \\
\text { (B) }\end{array}$ & $\begin{array}{l}\text { Controlled } \\
\text { Wafer } \\
\text { (C) }\end{array}$ \\
\hline Substrate Si P(100) & $\mathrm{X}$ & $X$ & $X$ \\
\hline Coating of resist $* 1$ & $X$ & $\mathrm{X}$ & - \\
\hline Removal of resist by adhesive tape (RRT) & $\mathrm{X}$ & - & - \\
\hline Removal of resist by $\mathrm{O}_{2}$ plasma & - & $X$ & - \\
\hline Repeat from coating to removal & $X$ & $X$ & - \\
\hline Rinse before diffusion & $X$ & $\mathrm{X}$ & - \\
\hline Oxidation (13.5nm) & $X$ & $X$ & $X$ \\
\hline
\end{tabular}

\section{RESULTS}

\begin{tabular}{|ll|c|c|c|}
\hline Life time $(\tau) * 3$ & $/ \mu \mathrm{s}$ & 407.9 & 189.7 & $200 \sim 300$ \\
\hline Density of crystalline defects*4 & $/ 1 \mathrm{e} 10 \mathrm{~cm}^{-3}$ & 0.33 & 16.5 & - \\
\hline Flatband voltage $\left(\mathrm{V}_{\mathrm{fb}}\right)^{* 5}$ & $/ \mathrm{V}$ & -0.375 & -0.373 & $-0.35 \sim 0.4$ \\
\hline Density of interfacial levels $\left(\mathrm{D}_{\mathrm{it}}\right)^{* 5}$ & $/ \mathrm{cm}^{-2} \mathrm{eV}$ & $4.04 \mathrm{e} 10$ & $4.64 \mathrm{e} 10$ & $4 \sim 8 \mathrm{e} 10$ \\
\hline
\end{tabular}

* 1 Coating of the resist: according as Table 2 except for patterning and ion implantation.

*2 Resist: PFR-IX570EDM9 ${ }^{\mathrm{R}}$ posi-type phenolnovolak (Japan Synthetic Rubber Co. Ltd.)

$\mathrm{O}_{2}$ plasma asher: OPM-2001CN (Tokyo Ohka Kogyou Co.) coaxial type

$\mathrm{UV} / \mathrm{O}_{3}$ asher: $\mathrm{UA3150 \textrm {A }}$ (Hitachi Ltd.) low pressure mercury lamp $+\mathrm{O}_{3}$ at $\mathrm{RT}$ for $1 \mathrm{~min}$

RRT: RR-5000 (Nitto Denko Co.) resist removal process $+\mathrm{UV} / \mathrm{O}_{3}$ ashing at $\mathrm{RT}$ for $1 \mathrm{~min}$

*3 LTA550 (Genesis Technology Inc.)

*4 SPV Station (Japan ADE Ltd.)

*5 CV 8000-L (Dainippon Screen Mfg. Co. Ltd.)

ashing indicated only a few fragment peaks compared that from before ashing. The results corresponded to the XPS data. And the fragment peaks were inferred to be contamination from the environment of the measurement.

3.4 Electrical properties of wafer after the resist removal process

Lifetime $(\tau)$, flatband voltage $\left(\mathrm{V}_{\mathrm{fb}}\right)$, density of crystalline defects, and density of interfacial levels $\left(D_{i t}\right)$ were measured to compare the quality of oxide layer and substrate after the resist removal process by the tape and by $\mathrm{O}_{2}$ plasma ashing. The results for 3 kinds of wafers are shown in Table 5. The procedures from exposure to removal of the resist were repeated two times to enhance the effects.

Lifetime was significantly longer using RRT than that by $\mathrm{O}_{2}$ plasma ashing. Moreover, the density of crystalline defects was $1 / 30$. Influence of metal contamination was in accordance with the results of TXRF. Since the preparation of samples was identical, except for the method of removal of the resist, the differences seen must be a result of the method of removal. $V_{f b}$ and $D_{i t}$ of both types of samples were the same levels as the control wafer.

\section{Discussion}

The results of the experiments mentioned above indicate that the coated resist was removed by RRT by the proposed process: the monomer contained in the adhesive penetrated to the resist layer, thereby allowing for delamination of the resist when the RRT was peeled off. The incorporation of the monomer into the resist was proved by in situ observation on diffusion of the monomer.

Many investigations have been made on the diffusion of small molecules through polymers ${ }^{24)}$ ${ }^{-30)}$. Goebel et al. studied diffusion of chlorinated hydrocarbons through polymeric membranes to evaluate behavior of a sensor in water by ATR in which they used a polymer coated ATR prism for their ATR measurements. They found that a classical Fickian response was dominant for the diffusion of chlorinated hydrocarbons in the 
Infrared light (IR)

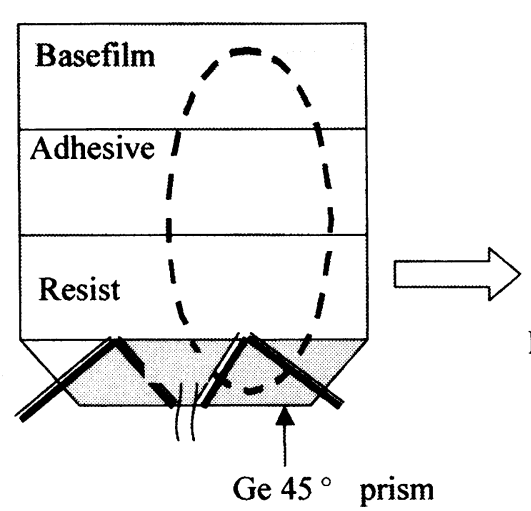

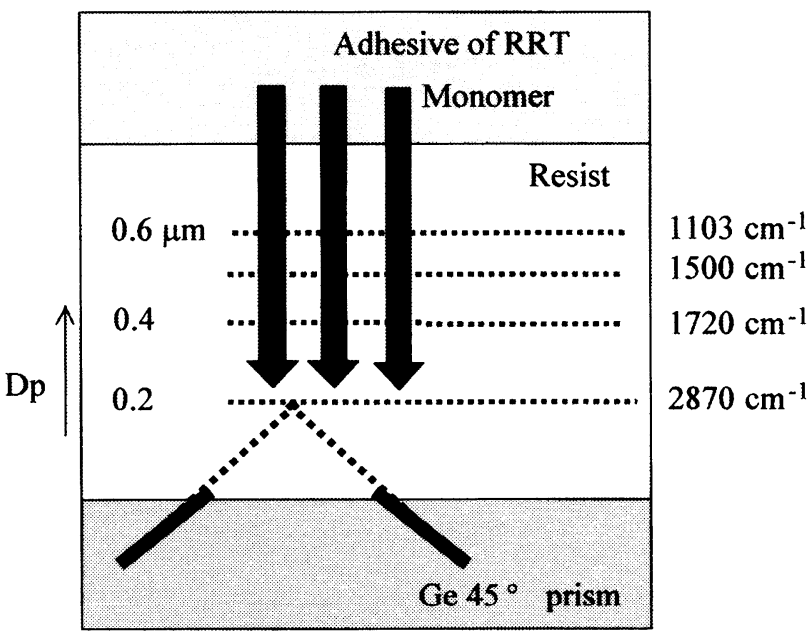

Figure 4. Geometry of ATR measurement

membrane.

\subsection{Penetration of the monomer in the resist layer}

The observations for penetration of the monomer into the resist layer were carried out in situ by the method called attenuated total reflection by infrared light (ATR). The observation of the resist on the wafer was difficult due to the thinness of the wafer and absorption of $\mathrm{Si}$ at the wavenumber less than $1000 \mathrm{~cm}^{-1}$. So, the model as stated below was used for these observations. The model shown in Figure 4 has the characteristic that the resist is coated directly on the Ge ATR prism, and the adhesive tape containing the monomers was attached on the resist at 296K. Fourier Transform infrared spectrometer (FT-IR), Spectrum2000 (Perkin Elmer Co.) was used at the resolution of $4 \mathrm{~cm}^{-1}$.

It is well known that Infrared (IR) light is totally reflected by the prism wall, however IR is able to penetrate into the sample attached on the prism. The wave that penetrates into the sample is called an evanescent wave. An evanescent wave penetrates into the sample by penetration depth $\left(\mathrm{d}_{\mathrm{p}}\right)^{31)}$, at which the intensity of the evanescent light

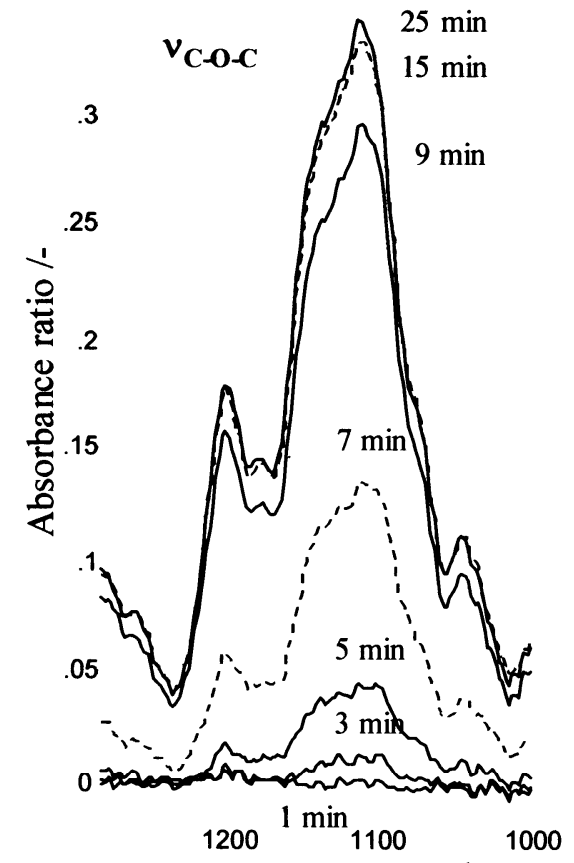

Wave number $/ \mathrm{cm}^{-1}$
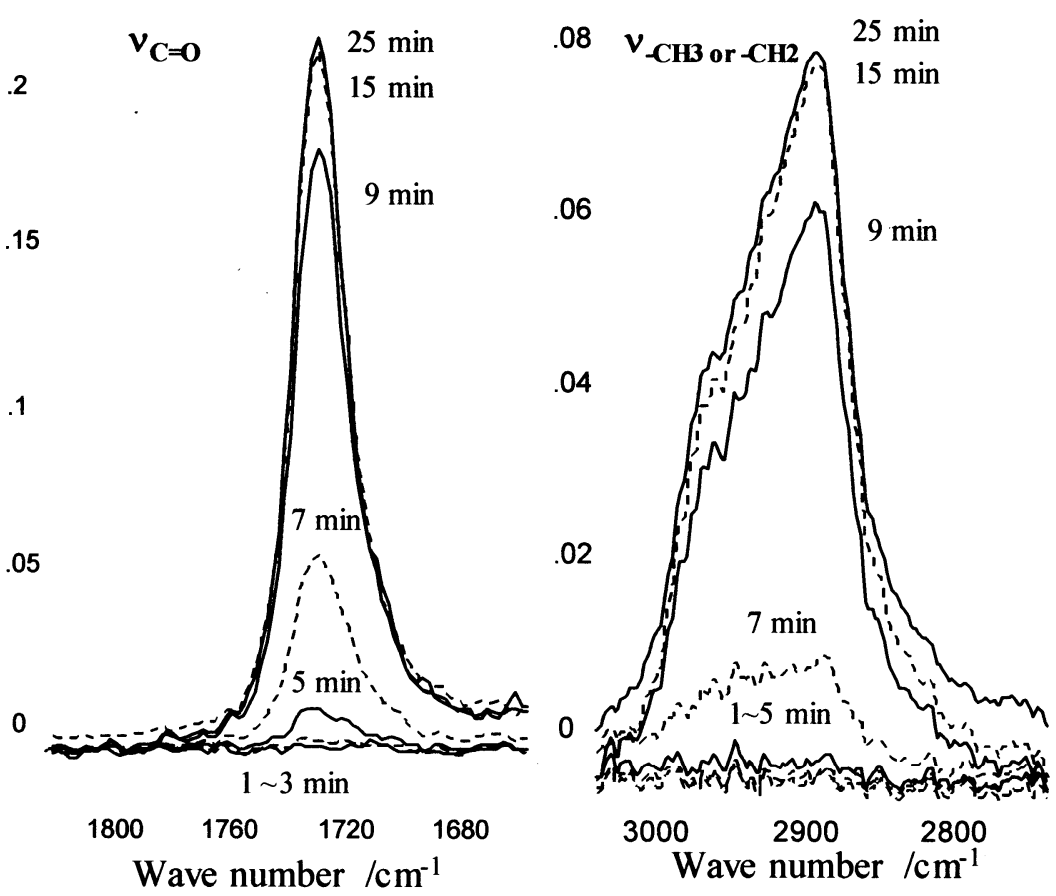

Figure 5. Time dependence of ATR spectra assigned to the monomer by diffusion through the resist 


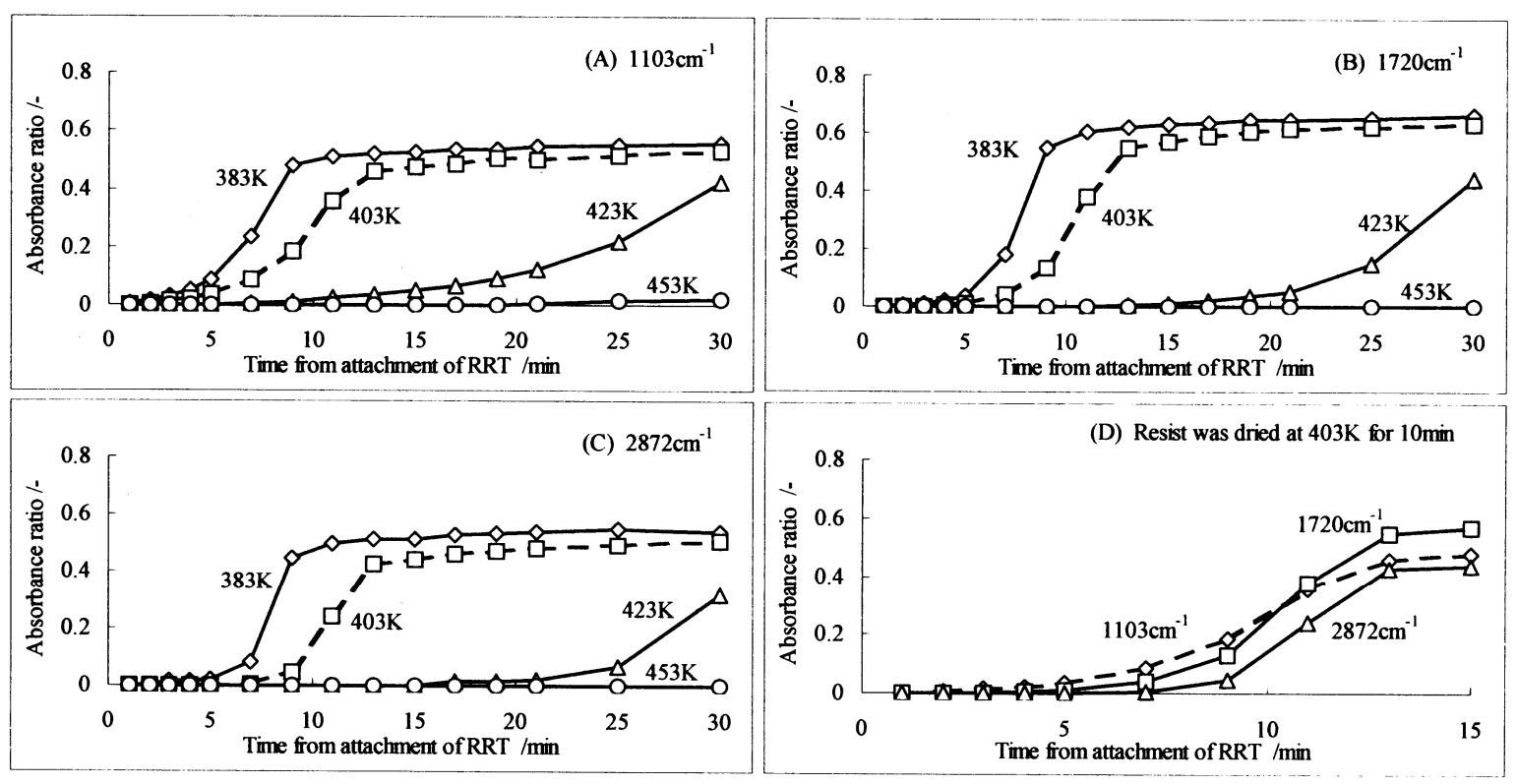

Figure 6. Dependence of the absorbance ratio of the monomer on the dried conditions of the resist

attenuates to $1 / \mathrm{e}$ of the incident light, calculated by the equation (1) and is absorbed by the sample material to give ATR spectrum.

$d_{p}=\lambda / 2 \pi n_{1}\left(\sin ^{2} \theta-\left(n_{2} / n_{1}\right)^{2}\right)^{1 / 2}$

where $\lambda$ is wavelength of IR (nm), $n_{1}$ and $n_{2}$ are refractive index of the prism and the sample, respectively, and $\theta$ is incident angle of IR to prism wall. Ge $45^{\circ}$ prism was selected for small $d_{p}$ and high sensitivity. For the system studied in this paper, $\mathrm{n}_{1}$ was 4.00 , and $\mathrm{n}_{2}$ was 1.51 . The observed wave numbers were $1103 \mathrm{~cm}^{-1}, 1500 \mathrm{~cm}^{-1}, 1720 \mathrm{~cm}^{-1}$, $2872 \mathrm{~cm}^{-1}$, which translates to $d_{p}$ values about 0.6 , $0.45,0.4$, and $0.2 \mu \mathrm{m}$, respectively. The variables of experiments were the baking temperature after coating, and dose of implantation of the prism. The background of ATR measurement was the absorption by the prism and the resist that didn't change by the handling of ATR measurement for at least $1 \mathrm{hr}$.

The measurements of one series was carried out using one prism and with a set placement within the ATR during the measurement.

The observed spectra varied according to the amount of penetration of the monomer within the resist. At the first stage, the observed spectrum indicated only the absorption by the resist, but as time went on the spectra indicated a mixed composite of the resist and the penetrant.

The subtract factor $(\mathrm{F})$ was determined to be 0 for the absorption peak at $1500 \mathrm{~cm}^{-1}$ by the subtraction of the resist spectrum from each mixed spectra. Therefore, $\mathrm{F}$ indicates the fraction of the resist in the observed region around $1500 \mathrm{~cm}^{-1}$ and the quantity of the penetrant in the region can be estimated by $F$. If $F=1$, the observed region comprised of only the resist without the penetrant, and conversely if $\mathrm{F}=0$, the observed region is full of the penetrant. The fraction of the resist in the region decreased as time went on and the baking temperature of the resist affected the penetration. If the resist was baked at $383 \mathrm{~K}$ the fraction of the penetrant reaches to about $60 \%$ in the mixture, however, the penetration didn't occur if the resist was baked at $453 \mathrm{~K}$.

The subtracted spectra are shown in Figure 5. The peaks shown in Figure 5, for example, originated from the monomer contained in the adhesive of RRT. The peaks other than those caused by the monomer couldn't be recognized from the subtracted spectra. The three peaks that were selected to observe the penetration of monomers were $1103 \mathrm{~cm}^{-1}\left(v_{\mathrm{C}-\mathrm{O}-\mathrm{C}}\right), \quad 1720 \mathrm{~cm}^{-1}\left(v_{\mathrm{C}=\mathrm{O}}\right), \quad$ and $2872 \mathrm{~cm}^{-1}\left(v_{\mathrm{C}-\mathrm{H}}\right)$.

The relationship of absorbance ratio to the time after the attachment of RRT is shown in Figure 6 (A)-(D). The absorbance ratio is defined as the normalized value of the measured absorbance divided by the corresponding absorbance when the prism is fully covered by monomer. The fraction of monomer in the resist layer can then be estimated by it. If the absorbance ratio is 1 , the observed region is occupied only by the monomer, and if the absorbance ratio is 0 then the region is full of the resist, meaning, the monomer doesn't penetrate to 
Table 6. Results of removal for resists prepared at various heat conditions

\begin{tabular}{|c|c|c|c|}
\hline \multicolumn{4}{|c|}{ Resist baking condition (for 10 min, respectively) } \\
\hline $383 \mathrm{~K}$ & $403 \mathrm{~K}$ & $423 \mathrm{~K}$ & $453 \mathrm{~K}$ \\
\hline $\begin{array}{c}\text { Perfectly } \\
\text { Removed }\end{array}$ & $\begin{array}{c}\text { Perfectly } \\
\text { Removed }\end{array}$ & $\begin{array}{c}\text { Partially } \\
\text { Removed }\end{array}$ & Not removed \\
\hline
\end{tabular}

the region. As shown in Figure 6 (A)-(C), the observed absorbance region in a resist dried at $383 \mathrm{~K}$ for $10 \mathrm{~min}$ consisted of the resist and monomer with the fraction of monomer being approximately $50 \%$. It can be seen that higher baking temperatures lead to smaller absorbance ratios indicating that the penetration of the monomer is slower in the resist baked at higher temperatures. In Figure 6 (D), the change of the values depended on the observed wave number. It was found that the change in absorbance ratio was observed sooner for lower wavenumbers however, the saturated values at $1103 \mathrm{~cm}^{-1}$ and $2872 \mathrm{~cm}^{-1}$ are lower than that at $1720 \mathrm{~cm}^{-1}$. The two kinds of monomers contained in the adhesive of RRT have different functions, with the peak at $1720 \mathrm{~cm}^{-1}$ being common to both of the monomers, while the other peaks correspond to the monomer that acts to solve the resist and be hardened by UV irradiation. As mentioned above, the monomers in the adhesive penetrate into the resist layer, but the rate of penetration depends on the baking conditions.

The resists were prepared on the control wafer using the various baking conditions as the model, and the resists were removed by RRT through the resist removal process. The results are shown in Table 6.

As shown in Figure 6 and Table 6, if the monomer didn't penetrate into the resist layer by some quantity, it was difficult to remove the resist. Spectral changes of the resists after baking are shown in Figure 7. The peak at about $3300 \mathrm{~cm}^{-1}$, assigned to hydroxyl group in phenol $\left(v_{\mathrm{O}-\mathrm{H}}\right)$, was shifted to a higher wavenumber accompanied by a decrease of absorbance of the peak around $1000 \mathrm{~cm}^{-1}$ which was assigned to hydroxyl group combined with alkyl group. The shift is associated with the change in the strength of the hydrogen bond in the phenol novolak resin. The crosslinking reaction with naphthoquinondiazide occurred in the resin by baking at high temperature, and the hydrogen bond in phenol novolak resin became weak due to steric hindrance around phenolic hydroxyl group.

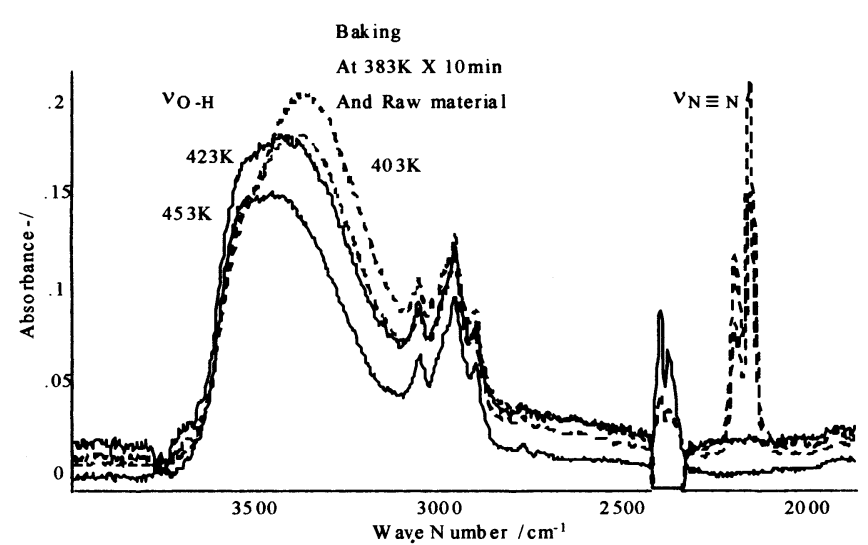

Figure 7. Change of ATR spectrum of the resist by heating

The crosslinking reaction by baking makes phenol novolak molecules more dense which masks the hydrophilic parts thereby making the resist hydrophobic. It then becomes difficult for hydrophilic monomer to diffuse through the resist.

The analysis of atomic composition of the components by XPS supported the results mentioned above. The results are shown in Table 7, where "Adhesive" and "Resist" refer to the surface of RRT and resist before application, and "Resist/Adhesive" and "Wafer" refer to the surface of removed resist by RRT and the wafer surface after removal, respectively. The removal of resist was carried out according to the procedure described in the section 2.4 , and the wafers were same as the control wafers.

The atomic composition of the "Resist/Adhesive" was different from both origins, namely "Adhesive" and "Resist". The Atomic ratio of oxygen increased in the "Resist/Adhesive" and sulfur (S) decreased. The atomic ratio of oxygen in the monomer present in the adhesive was about $53 \%$, and the surface of "Resist / Adhesive" was proposed to be composed by mixture of resist and monomer.

RRT functioned according to the proposed mechanism for the resist removal as mentioned above.

Table 7. Atomic composition of components before and after resist removal

\begin{tabular}{|l|c|c|c|c|c|}
\cline { 2 - 7 } \multicolumn{1}{c|}{} & $\mathrm{O}_{1 \mathrm{~s}}$ & $\mathrm{C}_{1 \mathrm{~s}}$ & $\mathrm{~S}_{2 \mathrm{p}}$ & $\mathrm{N}_{1 \mathrm{~s}}$ & $\mathrm{Si}_{2 \mathrm{p}}$ \\
\hline Adhesive $*_{1}$ & 19.5 & 77.8 & - & - & - \\
\hline Resist $*_{1}$ & 14.3 & 84.9 & 0.8 & - & - \\
\hline Resist/Adhesive *2 & 26.3 & 73.4 & 0.4 & $(0.04)$ & - \\
\hline Wafer *2 & 54.3 & 15.1 & - & - & 30.6 \\
\hline *1: As cast, before application \\
-: Under the quantified limit
\end{tabular}




\subsection{The limit of the process}

Remaining particles on the wafer after the resist removal process increased as the implantation dose increased. The removal of the resist became difficult when the implantation dose exceeded $4 \mathrm{e} 12$ $P$ ions ${ }^{*} \mathrm{~cm}^{-2}$ due to the increase of particles.

The effect of ion implantation on the penetration of the monomer was also investigated. Following the coating of the resist on Ge prism, phosphorous ions were implanted at $80 \mathrm{KeV}$ for $1 \mathrm{e} 12,1 \mathrm{e} 13$, $1 \mathrm{e} 16$ ions $\cdot \mathrm{cm}^{-2}$, respectively. Thereafter, RRT was attached to the implanted resist surface in order to measure the penetration by ATR at $296 \mathrm{~K}$. The results of measurement were shown in Figure 8.

Absorbance at $1720 \mathrm{~cm}^{-1}$ assigned to $v_{\mathrm{C}=\mathrm{O}}$ of the monomer was normalized by the average absorbance of the last 5 points for each spectrum. As the implantation dose of phosphorous ions is increased, the normalized absorbance rose slower. When the implantation dose reached at 1 e16 ions. $\mathrm{cm}^{-2}$, the penetration of monomer didn't occur. Implantation at high ion dose caused the layer to harden on the surface of resist ${ }^{32)-37)}$.

The layer composed of diamond like carbon (DLC) was analyzed by Raman spectroscopy and found to prevent the monomer from penetrating into the resist. The resist implanted at high dose over $1 \mathrm{e} 13$ ions $\cdot \mathrm{cm}^{-2}$ couldn't be removed by the examined process because the monomer didn't penetrate into the resist.

Thus, the resist that was implanted at the dose over $1 \mathrm{e} 13$ ions $\cdot \mathrm{cm}^{-2}$ and was treated at the temperature over $413 \mathrm{~K}$ couldn't remove from the wafer by the examined process. The results of removal changed depending on the properties and

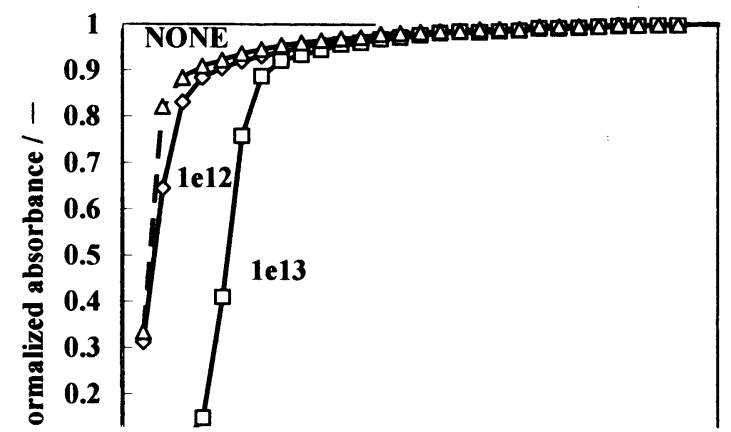

Figure 8. Effect of ion implantation dose on penetration of monomer measured in situ by ATR

the treatment of resist. The removal of tougher resist, the resist implanted at higher dose $\left(\sim 1 \times 10^{16}\right.$ ions $\left.\cdot \mathrm{cm}^{-2}\right)$ or higher energy $(\sim 3 \mathrm{MeV})$, proved almost successful, but the mechanism used for the removal is different from the mechanism described in this paper.

\subsection{Conclusion}

1) The resist implanted at $1 \mathrm{e} 12 \mathrm{P}$ ions $\cdot \mathrm{cm}^{-2}$ was removed from the wafer by RRT, and the particle residue over $0.2 \mu \mathrm{m}$ in diameter left behind was less than 10 counts on 5 " wafer.

2) The metallic contamination due to the resistremoval process by RRT is significantly less than that by $\mathrm{O}_{2}$ plasma ashing.

3) Both life time $\tau$ and density of crystalline defects were remarkably improved in the examined RRT process, comparing to the $\mathrm{O}_{2}$ plasma ashing process, because of less metallic contamination in the substrate and the oxide layer.

4) A thin organic layer less than $5 \mathrm{~nm}$ thick remaining on the wafer surface after removal of the resist by RRT process were easily eliminated by $\mathrm{UV} / \mathrm{O}_{3}$ ashing for a minute. The surface after $\mathrm{UV} / \mathrm{O}_{3}$ ashing was determined to be clean by XPS and TDS-APIMS.

5) The method for the in situ observation of the monomer penetration was presented. The mechanism of the resist removal can be explained by the penetration of monomers into the resist layer, the consolidation of monomer and resist, and delamination in the vicinity of interface between the resist/monomer mixture and the wafer surface.

6) The resist baked at high temperatures and/or severely implanted resists were difficult to remove by RRT in this study, because DLC layer prevented monomer diffusion.

7) The authors presume that the examined process can contribute to the manufacturing processes of front-edge devices by reducing the damage and contamination to wafers.

\section{Acknowledgement}

This work was performed under the collaboration of Hitachi Ltd. and Nitto Denko Corp. The Authors wish to thank Mrs. Tomoko Jimbo and her colleagues of Hitachi Ltd. for their advice and painstaking cooperation, and appreciate coworkers in Nitto Denko Corp. and Nitto Denko Technical Corp. for their support of this work.

\section{Refererences}

1. H.Kalter, E.P.G.T. van de Ven, Electrochem. Soc. Ext. Abs., 76(1) (1976) 335-337.

2. G.Bell, R. Stokan, ibid., 77 (2) (1977) 383-385.

3. Y. Kawamoto, Proc. 7th Symp. Dry Processing, 7 
(1985) 132-137.

4. K. Tsunokuni, K. Nojiri, S. Kuboshima, K. Hirobe, Ext.Abst.19th Conf. Solid State Devices Mat., Tokyo (1987) 195-198.

5. S. Fujimura, H. Yano, J.Electrochem. Soc., 135(5) (1988) 1195-1201.

6. S. Samukawa, Proc. Dry Process Symp., 11th (1989) 80-84.

7. D. L. Flamm, Solid State Tech., 35(8) (1992) 37-39.

8. D. L. Flamm, ibid., 35(9) (1992) 43-48.

9. H. Shin, C. King, C. Hu, Annu. Proc. Relia. Phys., 30th (1992) 37-41.

10. P. Burggraaf, Semiconductor International, June (1992) 66-69.

11. K. Hirose, H. Shimada, S. Shimomura, M. Onodera, T. Ohmi, J. Electrochem. Soc., 141(1) (1994) 192-205.

12. H. Okano, Electrochem. Soc. Ext. Abst., 88(1) (1988) 159-160.

13. S. Fujimura, T. Suzuki, K. Shinagawa, M. Nakamura, Proc. Dry Process Symp., 12th (1990) 153-156.

14. M. Kikuchi, R. L. Bersin, ibid., 13th (1991) 131-136.

15. S. Noda, M. Miyamoto, H. Horibe, $M$. Kuzumoto, T. Kataoka, J. Electrochem. Soc., 150(9) (2003) G537-G542.

16. S. Noda, K. Kawase, H. Horibe, M. Kuzumoto, T. Kataoka, ibid., 152(1) (2005) G73-G82.

17. N. C. Fuller, A. Santiago, K. Mello, C. Yu, S. Molis, Proc. 2006 IEEE/SEMI Adv. Semicond. Manuf. Conf. Workshop, (2006) 289-291.

18. H. Horibe, M. Fujita, I. Nishiyama, A. Yoshikado, Jpn. J. Appl. Phys., 44(12) (2005) 8673-8675.

19. H. Horibe, T. Kamimura, T. Hata, M. Yamamoto, I. Yamato, O. Nigo, M. Fujita, A. Yoshikado, and K. Yoshida, Polymer J., 37(11) (2005) 813-817.

20. H. Horibe, J. Photopolym Sci. Technol., 18(6)
(2005) 665-671.

21. H. Horibe, M. Fujita, A. Yoshikado, $J$. Electrochem. Soc., 153(7) (2006) G609-G612.

22. T. Kubozono, Y. Moroishi, Y. Ohta, H. Shimodan, N. Moriuchi, Proc. SPIE, 2724 (1996) 677-689.

23. E. Toyoda, M. Namikawa, S. Shirai, S. Sakai, Y. Yanagisawa, Proc. Dry Process Symp., 12th (1997) 139-144.

24. J. R. Xu, C. M. Balik, Appl. Spectrosc., 42(8) (1988) 1543-1548.

25. T. P. Skourlis, R. L. Mccullough, J. Appl. Polym. Sci., 52 (1994) 1241-1248.

26. R. Goebel, R. W. Seitz, S. A. Tomellini, R. Krska, R. Kellner, Vib. Spectrosc., 8 (1995) 141-149.

27. A. S. Cantor, J. Controlled Release, 61 (1999) 219-231.

28. Y. A. Elabd, T. A. Barbari, AIChE J., 48(8) (2002) 1610-1620.

29. Y. A. Elabd, M. G. Baschetti, T. A. Barbari, $J$. Polym Sci. B, 41 (2003) 1794-2807.

30. P. McLoughlin, K. Flavin, P. Kirwan, B. Murphy, K. Murphy, Sensor and Actuators B, 107 (2005) 170-177.

31. N. J. Harrick, J. Opt. Soc. Am., 55 (1965) 85.

32. Y. Okuyama, T. Hashimoto, T. Koguchi, $J$. Electrochem. Soc., 125(8) (1978) 1293-1298.

33. K. J. Orvek, C. Huffman, Nuclear Inst. Meth. Phys. Research, B7/8 (1985) 501-506.

34. S. Fujimura, H. Yano, ibid. B39 (1989) 809-812.

35. S. Fujimura, J. Konno, K. Hikazutani, H. Yano, Jap. J. Appl. Phys., 28(10) (1989) 2130-2136.

36. I. Tohno, M. Saito, K. Omiya, Y. Kataoka, ibid., 40 (2001) 798-802.

37. N. Nagai, T. Imai, K. Terada, H. Seki, H. Okumura, H. Fujino, T. Yamamoto, I. Nishimura, A. Hatta, Surf. Interface Anal., 34 (2002) 545-551. 